\title{
Response of coleoptiles to water deficit: growth, turgor maintenance and osmotic adjustment in barley plants (Hordeum vulgare L.)
}

\author{
Águeda González ${ }^{1^{*}}$, Luís Ayerbe ${ }^{2}$ \\ ${ }^{1}$ Departamento de Investigación Agroambiental, Alcalá de Henares, Spain; *Corresponding Author: agueda.gonzalez@madrid.org \\ ${ }^{2}$ Centro de Recursos Fitogenéticos, Alcalá de Henares, Spain.
}

Received 11 January 2011; revised 23 May 2011; accepted 25 July 2011.

\begin{abstract}
Cereal crop improvement programmes involve the analysis of a great number of lines every year; the availability of a simple, rapid method that would allow the identification of a trait in the early stages of plant development would facilitate the selection process. This work reports two experiments involving the germination of seeds in Petri dishes, performed to study the effect of water deficit on the growth of barley coleoptiles. In one experiment water stress was induced by allowing evaporation from the Petri dishes; in the other water stress was achieved by adding polyethylene glycol 6000 .

The growth of the control coleoptiles was greater than that of the treatment coleoptiles in all cases, but with differences between the different genotypes. A significant correlation $(P<$ 0.01 ) was found between the relative growth of the coleoptiles and turgor maintenance in the seedlings. Significant correlations were also seen between the relative growth of the coleoptiles and the osmotic adjustment of the flag leaf $(P<0.05)$ and the grain weight $(P<0.01)$ in adult plants. The genotypes that showed the greatest relative growth also showed the greatest capacity for osmotic adjustment in the flag leaf and produced the greatest yields in experiments with adult plants. The results indicate that the growth of coleoptiles subjected to water deficit could be used as a selection criterion in breeding programmes designed to improve the tolerance of barley to drought.
\end{abstract}

Keywords: Barley; Drought Tolerance; Water Potential; Osmotic Potential; Grain Yield

\section{INTRODUCTION}

Obtaining high, stable yields is a priority aim of cereal improvement programmes. In environments affected by drought the improvement of yield is difficult given the low heritability of this trait and because of the variable quantity and temporal distribution of soil water. The use of secondary traits, including physiological traits [1], has been proposed as a possible solution to this problem. In this approach the identification of traits that contribute towards drought tolerance and that can be used as selection criteria in improvement programmes is essential for increasing selection efficiency, especially in climates in which water availability is low.

Unfortunately, the majority of physiological traits associated with drought tolerance that could be used as selection criteria are not easy to measure, and physiological screening tests are complex and slow when a large number of genotypes are involved. These problems can be minimised, however, if traits of interest can be measured in the first stages of development with plants growing in controlled environments as long as these measures are sufficiently closely correlated with drought tolerance at crop level. Under such conditions the selection process can be much more quickly and efficiently undertaken - many genotypes can be studied at once and the time and space required for tests to be performed are reduced. Coleoptile length has been identified as one interesting trait for improving drought tolerance. Final coleoptile length is under the control of many genes and regulated by environment. The expression of these genes is differentially affected by the drought stress applied [2]. Heat-stress was associated with a decrease in the rate of growth and in the final length of barley and wheat coleoptiles [3,4]

Osmotic adjustment is becoming increasingly recognised as an efficient drought tolerance mechanism in cultivated plants $[5,6]$, exerting a positive effect-either 
directly or indirectly—on the productivity of plants that grow under drought conditions [7]. Genotypes with the ability to make osmotic adjustments produce greater yields; for example in chickpea [8,9], pea [10], sorghum $[11,12]$, wheat $[13,14]$, barley $[15,16]$, sunflower [17] and potato [18] .

Osmotic adjustment consists in the active accumulation of solutes in cells as a response to a reduction in the water potential. This leads to cells retaining water and a consequent tendency to retain their turgor pressure under water deficit. Osmotic adjustment reduces the sensitivity of processes dependent on turgor, such as growth and stomatal activity, when the water potential falls [19].

Genetic variation is essential for a trait to be used as a selection criterion in improvement programmes. The existence of intraspecific variability with respect to osmotic adjustment $[6,16,17,19,20-22]$ and coleoptile growth $[23,24]$ has been demonstrated in different crops. This, along with the possibility of identifying QTLs that control drought tolerance in seedling [25], and coleoptile growth [26], renders the study of coleoptile growth of great interest in the improvement of drought tolerance.

Differences in osmotic adjustment capacity can be measured in adult plants. However, it is not easy to measure in the very great numbers of lines that a breeding programme handles every year. The aims of the present work were to: 1) understand the response of different barley genotypes to water deficit in their first weeks of growth, 2) to determine whether any differences exist in the growth of coleoptiles of different barley genotypes under water deficit conditions, and 3) to study the relationship between osmotic adjustment of the coleoptiles and that of adult plants.

\section{MATERIALS AND METHODS}

\subsection{Plant Materials and Stress Treatments}

Eight barely genotypes were used in the present work, including three improvement lines from ICARDA (L31, L40 and L47) and five commercial varieties (Tipper, Plaisant, Viva, Reinette and Albacete). Experiments to determine the relationship between osmotic adjustment and growth were performed in a germination chamber following the method of Morgan [26]. Fourteen seeds were placed on germination paper in $13 \mathrm{~cm}$-diameter Petri dishes, with six dishes per genotype (three control dishes and three treatment dishes); $22 \mathrm{ml}$ of distilled water were then added to all the dishes. These dishes were then placed in a germination chamber at a constant temperature of $25^{\circ} \mathrm{C}-26^{\circ} \mathrm{C}$. After three days the lengths of the coleoptiles in every dish were measured.

Two water deficit experiments were conducted. In the first, water deficit was induced by allowing the evapora- tion of the water from the Petri dish. After measuring the length of the coleoptiles (initial length), the Petri dish lids were left off. In the control dishes the germination paper was placed over four $1 \mathrm{~cm}$-tall methacrylate supports, and water added beneath the paper to help maintain the moisture level. These control dishes were then placed once again in the germination chamber for $48 \mathrm{~h}$ at $26^{\circ} \mathrm{C}$ and at $90 \%$ relative humidity (RH). The germination paper was mounted in the same fashion in the treatment dishes, but these received no extra water. These plates were then placed in a germination chamber for $48 \mathrm{~h}$ at $26^{\circ} \mathrm{C}$ and at $70 \% \mathrm{RH}$. The lengths of the coleoptiles of both the treatment and control plants were then measured once more (final length).

In the second experiment, water deficit was induced by the addition of PEG (PEG-6000). Twenty millilitres of distilled water were added to each of the control dishes, while $20 \mathrm{ml}$ of PEG $(30 \% \mathrm{p} / \mathrm{v})$ were added to the treatment dishes. All these plates were then introduced into a germination chamber for $48 \mathrm{~h}$ at $26^{\circ} \mathrm{C}$ before measuring the coleoptiles again.

Relative growth was calculated as follows: (final length - initial length)/initial length.

\subsection{Measurements of Physiological Parameters}

The stress suffered by the plants was determined by measuring the water potential $(\Psi)$ and osmotic potential $\left(\Psi_{s}\right)$ using two coleoptiles from each dish. When the final length was obtained, they were placed in hygrometry chambers following the same procedure employed with adult plants [16]. Rectangular sections of the coleoptiles $\left(5.7 \mathrm{~cm}^{2}\right)$ were placed inside separate psychrometer chambers. The closed chambers were allowed to equilibrate in a water bath at $25^{\circ} \mathrm{C}$ for $3 \mathrm{~h}$. Measurements of $\Psi$ of the tissue were then made using a thermocouple hygrometer (Wescor model C-52, Logan, UT, USA) in dew point mode. The chambers containing the samples were then placed in a freezer at $-20^{\circ} \mathrm{C}$ for $2 \mathrm{~h}$. After thawing and equilibrating at $25^{\circ} \mathrm{C}$ for $3 \mathrm{~h}$, the $\Psi_{s}$ was determined. The turgor potential $\left(\Psi_{t}\right)$ was calculated as the difference between $\Psi$ and $\Psi_{s}$.

\subsection{Traits Associated with the Adult Plants}

The data for the adult plants used in this work are mean values for four years obtained during assays performed in a rain shelter, with plants growing under terminal water deficit conditions [27]. The rain shelter was divided into two areas (irrigated and water deficit conditions) separated by a $1.5 \mathrm{~m}$ wide central corridor. In the water deficit plots, each genotype was deprived of water when the plants reached the flag leaf stage, stage 41 on 
Table 1. Length and relative growth of coleoptiles of eight barley genotypes grown in Petri dishes under irrigated and water stress conditions by evaporative loss.

\begin{tabular}{|c|c|c|c|c|c|c|c|}
\hline \multirow[b]{2}{*}{ Genotype } & \multirow[b]{2}{*}{$\begin{array}{c}\text { Initial length } \\
(\mathrm{mm})\end{array}$} & \multicolumn{2}{|c|}{ Irrigated } & \multicolumn{2}{|c|}{ Water stress } & \multirow[b]{2}{*}{ Relative growth } & \multirow[b]{2}{*}{$\begin{array}{l}\text { Mean relative } \\
\text { growth }\end{array}$} \\
\hline & & $\begin{array}{l}\text { Final length } \\
\text { (mm) }\end{array}$ & Relative growth & $\begin{array}{c}\text { Initial length } \\
\text { (mm) }\end{array}$ & $\begin{array}{l}\text { Final length } \\
\text { (mm) }\end{array}$ & & \\
\hline $\mathrm{L} 31$ & 20.97 & 83.53 & 3.00 & 17.53 & 43.80 & 1.51 & 2.25 \\
\hline L40 & 21.43 & 91.60 & 3.28 & 24.23 & 61.03 & 1.53 & 2.40 \\
\hline L47 & 22.07 & 101.8 & 3.64 & 21.47 & 49.60 & 1.31 & 2.37 \\
\hline Tipper & 21.73 & 83.50 & 2.84 & 22.20 & 46.67 & 1.11 & 1.97 \\
\hline Plaisant & 29.60 & 103.1 & 2.49 & 29.60 & 55.57 & 0.88 & 1.68 \\
\hline Viva & 26.87 & 96.70 & 2.62 & 22.93 & 57.77 & 1.54 & 2.08 \\
\hline Reinette & 23.83 & 97.97 & 3.12 & 25.23 & 49.10 & 0.95 & 2.03 \\
\hline Albacete & 26.53 & 107.4 & 3.05 & 24.17 & 66.87 & 1.77 & 2.41 \\
\hline Mean & 24.13 & 95.70 & 3.00 & 23.42 & 53.80 & 1.32 & \\
\hline S.E.D* & & & 0.11 & & & 0.08 & 0.09 \\
\hline D.F. & & & 14 & & & 14 & 14 \\
\hline
\end{tabular}

*Standar error of mean diferences to compare genotypes under irrigated and water stress conditions.

the Zadoks scale [28]. Plots were arranged in four replications and the different genotypes distributed randomly in each of them.

Samples were taken from each plot from the beginning of the water stress treatment until maturity in order to estimate osmotic adjustment (OA). For this, weekly samples of flag leaves from one plant in each subplot were collected at 6:45 (GMT), placed in a sealable plastic bag, and transported to the laboratory. These leaves were then cut longitudinally into two symmetrical halves. One was immediately weighed in order to determine the relative water content (RWC) using the formula:

RWC (\%) $=[($ fresh weight - dry weight $) /$ turgid weight dry weight) $] \times 100$

The turgid weight was obtained by leaving overnight the same half of the leaf in destilled water at $5^{\circ} \mathrm{C}$ in darkness, and dry weight after $24 \mathrm{~h}$ at $80^{\circ} \mathrm{C}$. The other half was used to determine $\Psi_{s}$. To estimate the osmotic adjustment of each genotype, the correlation between $\Psi_{s}$ and $R W C$ was determined from the corresponding linear regressions. The RWC values for an $\Psi_{s}$ of $-3 \mathrm{MPa}$ was recorded following the criteria of Morgan (1983) [29].

The ears from the center square meter of each plot were threshed in a threshing machine and grain of each genotype was weighed.

\subsection{Statistical Analysis}

Genotype and stress treatments were analysed by performing two-way ANOVA analyses. When significant differences between treatments or genotypes were detected $(P<0.05)$, mean differences were compared with a $t$ test. The relationships between relative growth and the different variables examined were analysed by de- termining Pearson's correlation coefficients. Significance was determined using the Student t test. All calculations were performed using Statistica 5.1 software [30].

\section{RESULTS}

The effect of water deficit on coleoptile growth are presented in Tables 1 and 2 according to the water deficit was induced

\subsection{Water Deficit Induced by Evaporation}

Table 1 shows the growth data for the coleoptiles of the eight barley genotypes grown under control and water deficit, evaporation method, conditions. The mean growth of the control coleoptiles $(3 \mathrm{~mm})$ was significantly greater than that of the treatment coleoptiles $(1.32$ $\mathrm{mm})$ for all genotypes together, $(P<0.01)$. The growth of the controls was always greater than that of the treatment coleoptiles.

Differences were also detected, however, between the growth of the different genotypes, with three groups discernable. The group showing the greatest relative growth was composed of the genotypes L40, L47, Albacete and L31. This group was followed by one composed of Reinette and Viva. The group showing the least relative growth was made up of Plaisant and Tipper.

The correlation found between relative growth and $\Psi$ was high, non-significant for the controls but significant for the stress treatment plants $(P<0.05)$ (Figure 1).

\subsection{Water Deficit Induced by PEG}

Table 2 shows the mean relative growth values for the eight genotypes in the presence and absence of PEG. The 
Control

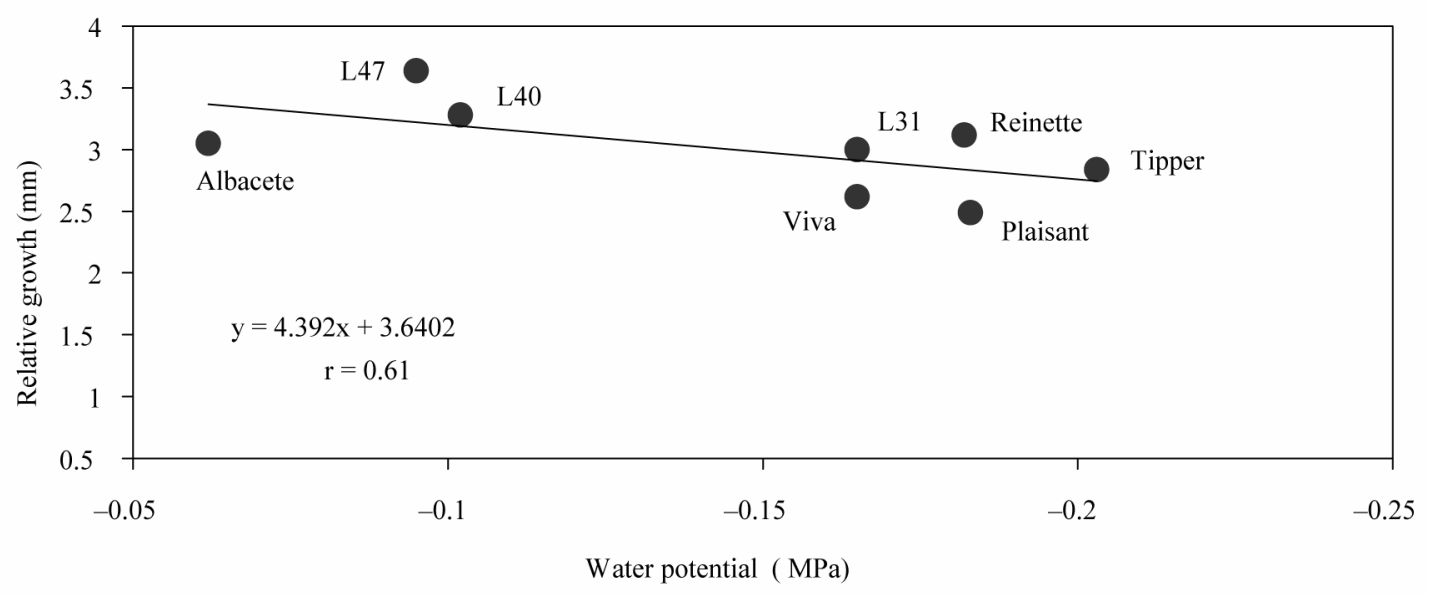

Stress

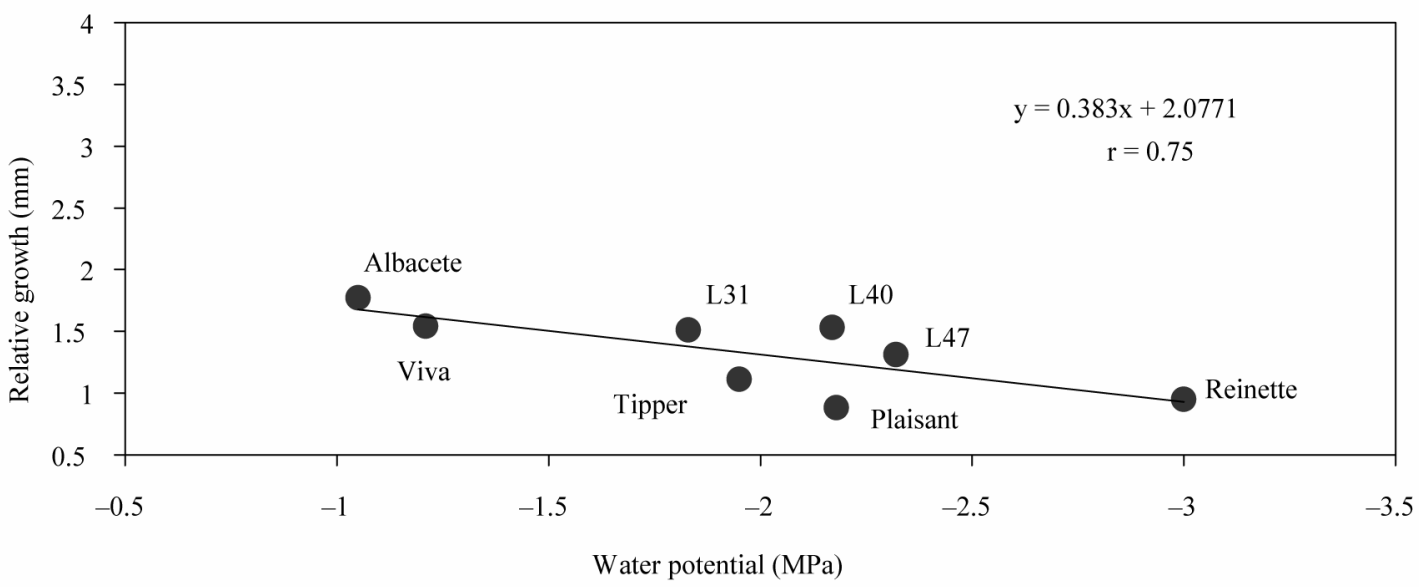

Figure 1. Relationship between relative growth of coleoptiles and water potential in control and water stress induced in evaporative loss of eight barely genotypes grown in Petri dishes.

mean relative growth of the control plants $(2.83 \mathrm{~mm})$ was significantly greater than that recorded for the treatment plants as a whole $(2.52 \mathrm{~mm})$ although the difference between the control and treatment was not significant for all genotypes.

Significant differences in relative growth were also seen between the different genotypes $(P<0.001)$. Again, three groups could be discerned. The first, with the greatest relative growth, included L31, L40 and L47, the second, with intermediate growth, included Tipper, Reinette and Albacete, and the third, with the least growth, included Plaisant and Viva.

The differences in growth between the control and treatment plants were smaller in this assay than in the previous assay for all genotypes. This may have been due to the dehydration process in the second experi- ment being slower, allowing time for the plants to bring into play water deficit tolerance mechanisms that favoured growth under these conditions (note that the growth of the control plants in both experiments is very similar and the correlation was significant $(r=$ $0.77, P<0.01$ ), while growth under the PEG stress conditions was greater than under the evaporation conditions and the correlation was not significant $(\mathrm{r}=$ $0.30)$.

\subsection{Maintenance of Turgor in the Coleoptiles}

The $\Psi$ of the control plants was greater than that of the treatment plants in both experiments and for all genotypes (Table 3). The $\Psi_{t}$ of the control plants was also higher in the control plants. The variety Plaisant and 
Table 2. Length and relative growth of coleoptiles of eight barley genotypes grown in Petri dishes with distilled water (control) and with a PEG solution (stress treatment).

\begin{tabular}{|c|c|c|c|c|c|c|c|}
\hline \multirow[b]{2}{*}{ Genotype } & \multirow[b]{2}{*}{ Initial length (mm) } & \multicolumn{2}{|l|}{ Irrigated } & \multicolumn{3}{|c|}{ Stress treatment } & \multirow[b]{2}{*}{$\begin{array}{l}\text { Mean relative } \\
\text { growth }\end{array}$} \\
\hline & & Final length (mm) & $\begin{array}{c}\text { Relative } \\
\text { growth }\end{array}$ & Initial length (mm) & Final length (mm) & $\begin{array}{l}\text { Relative } \\
\text { growth }\end{array}$ & \\
\hline L31 & 14.70 & 65.90 & 3.48 & 18.10 & 66.00 & 2.66 & 3.08 \\
\hline L40 & 18.93 & 78.47 & 3.15 & 18.47 & 74.87 & 3.05 & 3.10 \\
\hline L47 & 19.67 & 78.77 & 3.01 & 18.83 & 74.93 & 2.98 & 2.99 \\
\hline Tipper & 20.53 & 72.60 & 2.61 & 19.43 & 65.87 & 2.46 & 2.53 \\
\hline Plaisant & 28.37 & 92.90 & 2.29 & 27.90 & 85.90 & 2.08 & 2.18 \\
\hline Viva & 21.77 & 78.10 & 2.60 & 22.70 & 68.13 & 2.01 & 2.30 \\
\hline Reinette & 24.30 & 88.23 & 2.65 & 23.97 & 82.90 & 2.46 & 2.55 \\
\hline Albacete & 22.40 & 85.73 & 2.84 & 22.70 & 77.83 & 2.43 & 2.63 \\
\hline Mean & 21.33 & 80.09 & 2.83 & 21.50 & 74.55 & 2.52 & \\
\hline S.E.D.* & & & 0.24 & & & 0.18 & 0.17 \\
\hline D.F. & & & 14 & & & 14 & 14 \\
\hline
\end{tabular}

*Standar error of mean differences to compare genotypes under irrigated and stress conditions.

Table 3. Water potential $(\Psi)$, maintenance of turgor $(\Psi, \Psi=-2 \mathrm{MPa})$, osmotic adjustment $(\mathrm{OA})$ [Relative water content RWC $=$ $-3 \mathrm{MPa}]$, and grain yield under water stress conditions.

\begin{tabular}{|c|c|c|c|c|c|c|}
\hline \multirow[b]{3}{*}{ Genotype } & \multicolumn{4}{|c|}{ Coleoptiles } & \multicolumn{2}{|c|}{ Adult plant* } \\
\hline & \multicolumn{2}{|c|}{ Irrigated } & \multicolumn{2}{|c|}{ Water stress } & \multicolumn{2}{|l|}{ Flag-leaf } \\
\hline & $\Psi(\mathrm{MPa})$ & $\Psi_{t}(\Psi=-2 \mathrm{MPa})$ & $\Psi(\mathrm{MPa})$ & $\Psi_{t}(\Psi=-2 \mathrm{MPa})$ & $\mathrm{OA}(\mathrm{CHR}=-3 \mathrm{MPa})$ & Grain weight $\left(\mathrm{g} \cdot \mathrm{m}^{-2}\right)$ \\
\hline L31 & -0.165 & 0.189 & -1.83 & 0.116 & 72.51 & 215.84 \\
\hline L47 & -0.095 & 0.148 & -2.32 & 0.059 & 63.37 & 188.47 \\
\hline Tipper & -0.203 & 0.057 & -1.95 & 0.051 & 63.47 & 186.90 \\
\hline Plaisant & -0.183 & 0.201 & -2.18 & 0.021 & 62.28 & 151.05 \\
\hline Viva & -0.165 & 0.166 & -1.21 & 0.036 & 62.22 & 116.05 \\
\hline Reinette & -0.182 & 0.114 & -3.00 & 0.059 & 64.28 & 194.99 \\
\hline Albacete & -0.062 & 0.225 & -1.05 & 0.030 & 59.83 & 161.67 \\
\hline Mean & -0.145 & 0.156 & -1.964 & 0.057 & 64.92 & 187.31 \\
\hline
\end{tabular}

*All values are means of four years under water stress conditions (González 2001).

the breeding line L31 had the highest $\Psi_{t}$ values, 0.201 $\mathrm{MPa}$ and $0.189 \mathrm{MPa}$ respectively, while Tipper had the lowest, $0.057 \mathrm{MPa}$. In the PEG water deficit treatment the genotypes with the highest $\Psi_{t}$ values were L31 and L40, 0.116 $\mathrm{MPa}$ and $0.083 \mathrm{MPa}$ respectively, while Plaisant, Albacete and Viva had the lowest $\Psi_{t}$ values, $0.021 \mathrm{MPa}, 0.03 \mathrm{MPa}$ and $0.036 \mathrm{MPa}$ respectively. Reinette, Tipper and L47 showed intermediate $\Psi_{t}$ values. The osmotic adjustment behaviour of the genotypes in the PEG water deficit treatment was similar in the coleoptile stage to that seen in adult plants. Breeding lines L31 and L40 were those with the greatest osmotic adjustment capacity with relative water content (RWC) at -3 MPa of 72.51 and 71.39 respectively (Table 3). The varieties Plaisant, Viva and Albacete showed the lowest values at $62.28,62.22$ and 59.83 respectively. This explains the strong correlation found between the osmotic adjustment seen in the adult plants and seedling turgidity $(P<0.01)$ (Figure 2(a)), as well as the strong correlation seen between relative growth under water deficit and seedling turgidity (Figure 2(b)).

The correlations found between osmotic adjustment in the adult plants and the relative growth of the coleoptiles was not significant for the controls, but significant $(P<$ $0.05)$ for the water deficited plants in the PEG assay (Table 4). These correlations were less strong, non-significant, in the first experiment for both the control and treatment plants. This is probably due to the more rapid dehydration achieved with evaporation than the PEG treatment; such rapidity may have impeded the ability to make efficient use of adaptation mechanisms such as osmotic adjustment.

The correlation between grain weight and the relative growth of the coleoptiles was significant under the PEGinduced water deficit conditions, but not in the evaporation-induced water deficit conditions (Table 4).

The present results indicate that coleoptile growth is directly related to osmotic adjustment under water deficit conditions. Osmotic adjustment also has a positive effect on turgor, as shown by the positive, significant 


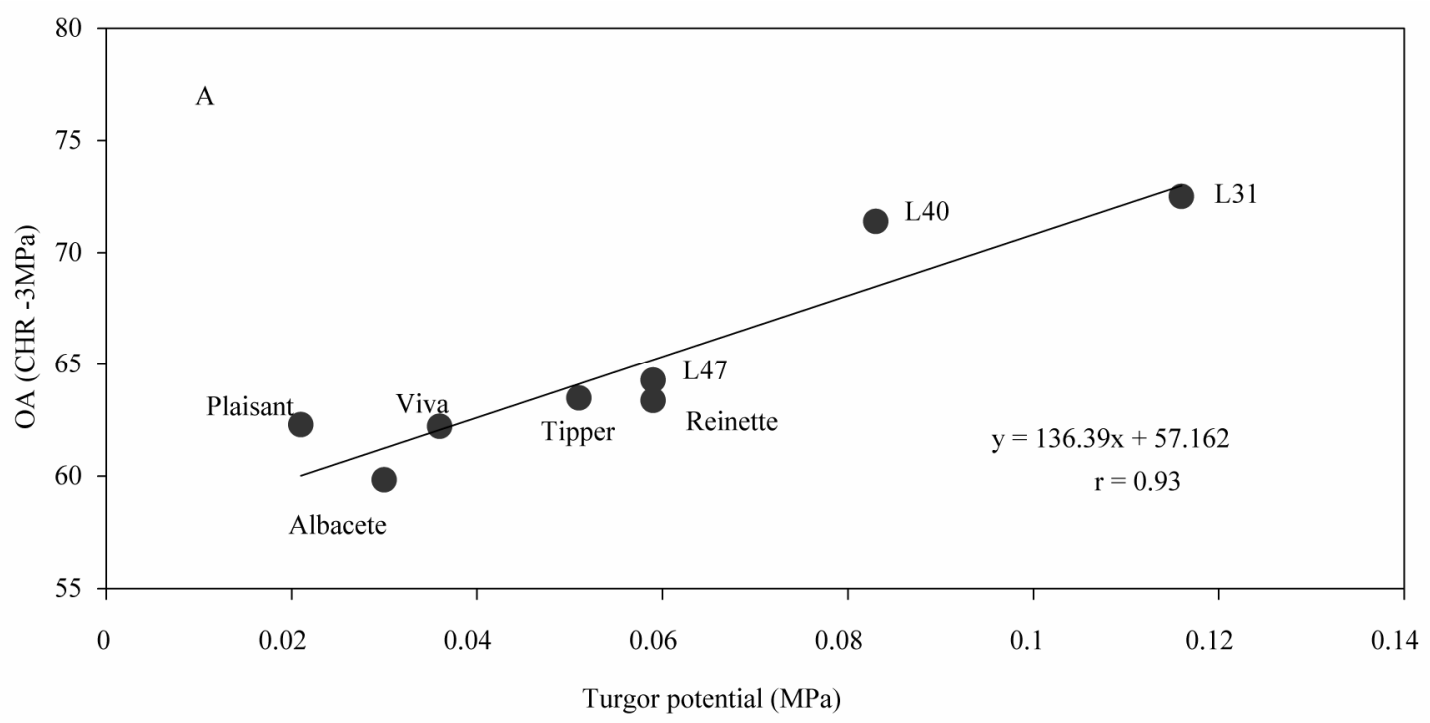

(a)

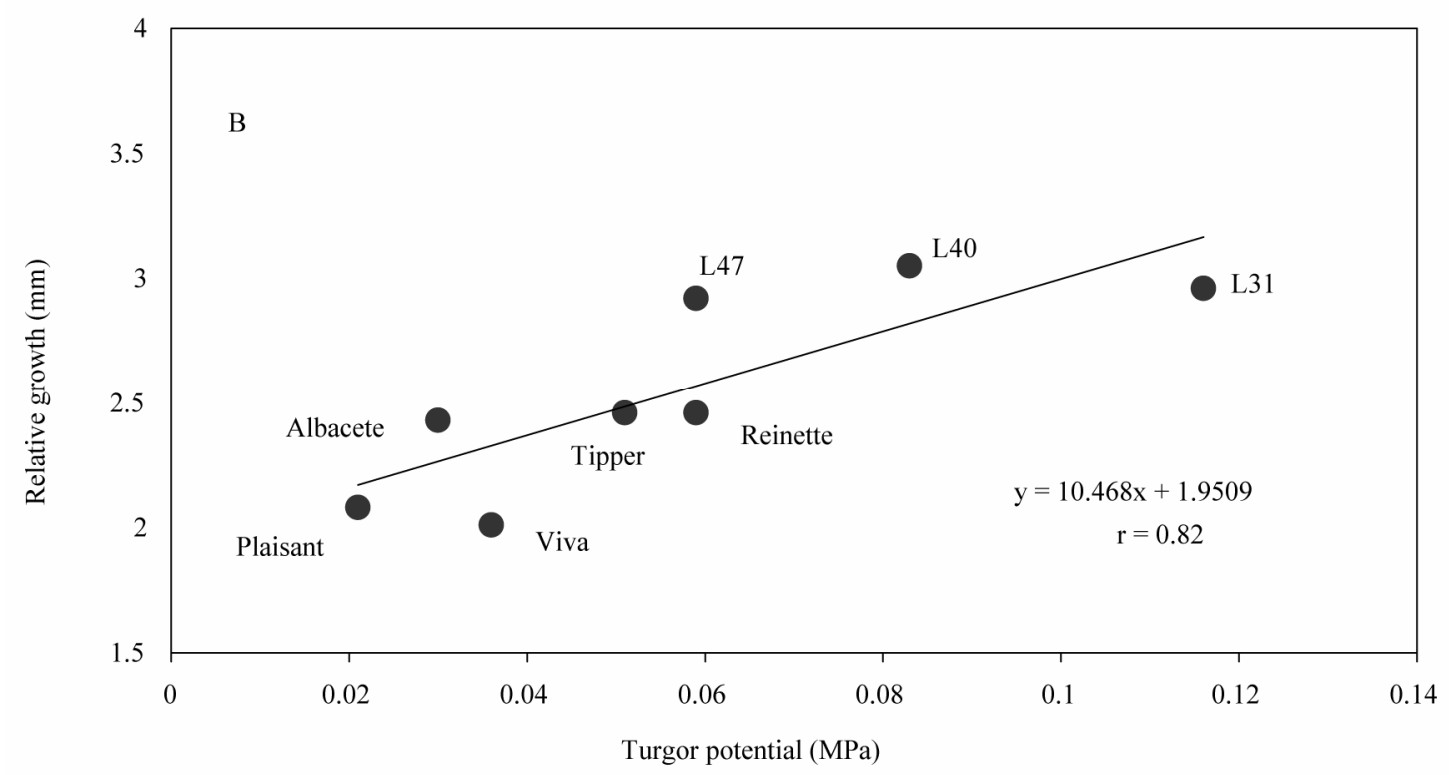

(b)

Figure 2. (a) Relationship in coleoptiles and osmostic adjustment estimate (OA) (RWC $=-3 \mathrm{MPa})$ in adult plant and (b) relative growth of coleoptiles grown in the presence of a PEG solution.

Table 4. Linear correlation coefficients between relative growth of coleoptiles under two water stress treatments and osmotic adjustment (OA) and grain yield in adult plant.

\begin{tabular}{|c|c|c|c|c|}
\hline & \multicolumn{2}{|c|}{ Evaporative loss } & \multicolumn{2}{|c|}{ PEG solution } \\
\hline & $\mathrm{OA}$ & Grain weight & $\mathrm{OA}$ & Grain weight \\
\hline $\begin{array}{l}\text { Relative } \\
\text { growth Con- } \\
\text { trol }\end{array}$ & 0.27 & 0.29 & 0.67 & 0.41 \\
\hline $\begin{array}{l}\text { Relative } \\
\text { growth Stress }\end{array}$ & 0.61 & 0.11 & $0.74 *$ & $0.86^{* *}$ \\
\hline
\end{tabular}

$*$, **significant at the 0.5 and 0.01 probability levels, respectively. correlation $(P<0.01)$ between seedlings turgor and osmotic adjustment in adult plants (Figure 2).

\section{DISCUSSION}

Variation was seen with respect to the growth of the coleoptiles under both control and treatment conditions. Similar results have been reported by other authors for wheat [31,32], triticale [32], and pea [33].

A significant correlation was obtained between the relative growth of the coleoptiles and $\Psi$ under evapora- 
tion-induced water deficit conditions (Figure 1). However, the correlation with osmotic adjustment was not significant. When water deficit was induced with PEG, the correlation between osmotic adjustment and relative growth was significant (Table 4). In the first case the mean relative growth of the control coleoptiles was $56 \%$ greater than that shown by those under water deficit (Table 1). In the PEG assay, however, this difference fell to just $11 \%$ (Table 2 ). This probably reflects a more efficient osmotic adjustment in the PEG assay, a consequence of the dehydration process being slower. The level of osmotic adjustment reached depends on factors such as the degree of water deficit and the rate at which it develops. The osmotic adjustment that occurs is less if water deficit develops quickly [34]. The results confirm the influence of osmotic adjustment on turgor maintenance and growth in barley coleoptiles under water deficit conditions. Similar results were obtained in rice and pearl millet $[22,35]$ who reported osmotic adjustment to be the trait that made the greatest contribution towards the maintenance of turgor and seedling growth under water deficit conditions. Studding the response of two wheat cultivars to osmotic stress induced by PEG, Guóth et al. [36] reported the water potential of the tolerant cultivar did not change significantly under stress conditions, whereas significant differences were observed in the sensitive cultivar. In sunflower it has been reported that, with respect to water status in the leaves, the ranking of the genotypes is maintained over the growth of the plants [37].

In both assays, L31 and L40 were among the genotypes showing the greatest growth, while Plaisant and Viva were among those with the relatively smallest growth. This classification corresponds with that found for osmotic adjustment in the adult plants, with L40 and L31 showing the greatest osmotic adjustment capacity and Plaisant and Viva the least (Table 3).

Both growth and the behaviour of the $\Psi_{t}$ for the barley genotypes studied were similar to those obtained for the flag leaf osmotic adjustment and grain weight, as confirmed by the correlation detected between osmotic adjustment in adult plants and the turgor maintained by the seedling $(P<0.01)$ (Figure 2(a)). In addition, the correlation found between the relative growth of the coleoptiles and grain weight was high $(P<0.01)$ under the PEG water deficit conditions. These results show the value of coleoptile growth in response to water deficit as a selection trait in barley breeding programmes. The correlation between coleoptile growth and yield under water deficit has also been reported for wheat (Moud and Maghsoudi 2008). The osmotic adjustment of adult barley plants correlates significantly $(P<0.01)$ with the ability to maintain turgor under water deficit conditions during the seedling stage (Figure 1), and grain yield correlates with coleoptile relative growth under water deficit conditions (Table 4). The present results indicate that seedlings studies offer advantages in barley selection programmes. More work should be performed in this area.

\section{REFERENCES}

[1] González, A., Bermejo, V. and Gimeno, B.S. (2010) Effect of different physiological traits on grain yield in barley grown under irrigated and terminal water deficit conditions. Journal of Agricultural Science, 148, 319-328. doi:10.1017/S0021859610000031

[2] Landjeva, S., Korzun, V., Stoimenova, E., Truberg, B., Ganeva, G. and Börner, A. (2008) The contribution of gibberelling-in-sensitive semi-dwardfing (Rht) genes to genetic variation in wheat seedling growth in response to osmotic stress. Journal of Agricultural Science, 146, 275 286.

[3] Cannell, R.Q. (1969) The tillering pattern in barley varieties: II. The effect of temperature light intensity and daylength on the frequency of occurrence of the coleoptile node and second tillers in barley. The Journal of Agricultural Science, 72, 423-435. doi:10.1017/S0021859600024849

[4] Onwueme, I.C. and Laude, H.M. (1972) Heat-induced growth retardation and attempts at its prevention in barley and wheat coleoptiles. The Journal of Agricultural Science, 79, 331-333. doi:10.1017/S0021859600032317

[5] Teulat, B., Rekika, D., Nachit, M.M. and Monneveux, P. (1997) Comparative osmotic adjustments in barley and tetraploid wheats. Plant Breeding, 116, 519-523. doi:10.1111/j.1439-0523.1997.tb02183.x

[6] Zhang, J., Nguyen, H.T. and Blum, A. (1999) Genetic analysis of osmotic adjustment in crop plants. Journal of Experimental Botany, 50, 291-302. doi: $10.1093 /$ jexbot $/ 50.332 .291$

[7] Hamidou, F., Zombre, G. and Braconnier, S. (2007) Physiological and Biochemical responses of cowpea genotypes to water deficit under glasshouse and field conditions. Journal of Agronomy \& Crop Science, 193, 229237. doi:10.1111/j.1439-037X.2007.00253.x

[8] Ludlow, M.M. and Muchow, R.C. (1990) A critical evaluation of traits for improving crop yields in water-limited environments. Advances in Agronomy, 43, 107-153. doi:10.1016/S0065-2113(08)60477-0

[9] Morgan, J.M., Rodríguez-Maribona, B. and Knights, E.J. (1991) Adaptation to water-deficit in chickpea breeding lines by osmoregulation: relationship to grain-yields in the field. Field Crops Research, 27, 61-70. doi:10.1016/0378-4290(91)90022-N

[10] Moinuddin, Khanna-Chopra, R. (2004) Osmotic adjustment in chickpea in relation to seed yield and yield parameters. Crop Science, 44, 449-455.

[11] Rodríguez-Maribona, B., Tenorio, J.L., Conde, J.R. and Ayerbe, L. (1992) Correlation between yield and osmotic adjustment of peas (Pisum sativum L.) under drought stress. Field Crops Research, 29, 15-22. doi, 10.1016/0378-4290(92)90072-H 
[12] Ludlow, M.M., Santamaria, J.M. and Fukai, S. (1990) Contribution of osmotic adjustment to grain yield in Sorghum bicolor (L.) moench under water-limited conditions. II. Water deficit after anthesis. Australian Journal of Agricultural Research, 41, 67-78. doi:10.1071/AR9900067

[13] Santamaria, J.M., Ludlow, M.M. and Fukai, S. (1990) Contribution of osmotic adjustment to grain yield in Sorghum bicolor (L.) moench under water-limited conditions. I. Water deficit before anthesis. Australian Journal of Agricultural Research, 41, 51-65. doi:10.1071/AR9900051

[14] Morgan, J.M. (1995) Growth and yield of wheat lines with differing osmoregulative capacity at high soil water deficit in seasons of varying evaporative demand. Field Crops Research, 40, 143-152. doi:10.1016/0378-4290(94)00100-Q

[15] Blum, A., Zhang, J. and Nguyen, H.T. (1999) Consistent differences among wheat cultivars in osmotic adjustment and their relationship to plant production. Field Crops Research, 64, 287-291. doi:10.1016/S0378-4290(99)00064-7

[16] González, A., Martín, I. and Ayerbe, L. (1999) Barley yield in water-stress conditions. The influence of precocity, osmotic adjustment and stomatal conductance. Field Crops Research, 62, 23-34. doi:10.1016/S0378-4290(99)00002-7

[17] González, A., Martín, I. and Ayerbe, L. (2008) Yield and osmotic adjustment capacity of barley under terminal water deficit conditions. Journal of Agronomy \& Crop Science, 194, 81-91. doi:10.1111/j.1439-037X.2007.00289.x

[18] Chimenti, C.A., Pearson, J. and Hall, A.J. (2002) Osmotic adjustment and yield maintenance under drought in sunflower. Field Crops Research, 75, 235-246. doi:10.1016/S0378-4290(02)00029-1

[19] Daneshmand, F., Harvin, M.J. and Kalantari, K.M. (2010) Physiological responses to $\mathrm{NaCl}$ stress in three wild species of potato in vitro. Acta Physiologiae Plantarum, 32, 91-101. doi:10.1007/s11738-009-0384-2

[20] Morgan, J.M. (1984) Osmoregulation and water deficit in higher plants. Annual Review of Plant Physiology, 35, 299-319. doi:10.1146/annurev.pp.35.060184.001503

[21] Blum, A. (1989) Osmotic adjustment and growth of barley genotypes under drought stress. Crop Science, 29, 230-233. doi:10.2135/cropsci1989.0011183X002900010052x

[22] Basu, S., Roychoudhury, A., Saha, P.P. and Sengupta, D.N. (2010) Comparative analysis of some biochemical responses of three indica rice varieties during polyethylene glycol-mediated water stress exhibits distinct varietal differences. Acta Physiologiae Plantarum, 32, 551- 563. doi:10.1007/s11738-009-0432-y

[23] Moud, A.M. and Maghsoudi, K. (2008) Application of coleoptile growth response method to differentiate osmoregulation capability of wheat (Triticum aestivum L.) cultivars. Research Journal of Agronomy, 2, 36-43.

[24] Murphy, K., Balow, K., Lyon, S.R. and Jones, S.S. (2008) Response to selection, combining ability and heritability of coleoptile length in winter wheat. Euphytica, 164, 709-718. doi:10.1007/s10681-008-9692-7
[25] Kato, Y., Hirotsu, S., Yamagishi, J. and Nemoto, K. (2008) Identification of QTLs controlling rice drought tolerance at seedling stage in hydroponic culture. Euphytica, 160, 423-430.

doi:10.1007/s10681-007-9605-1

[26] Rebetzke, G., Ellis, M., Bonnett, D. and Richards, R. (2007) Molecular mapping of genes for coleoptile growth in bread wheat (Triticum aestivum L.). Theorical and Applied Genetics, 114, 1173-1183. doi:10.1007/s00122-007-0509-1

[27] Morgan, J.M. (1988) The use of coleoptile responses to water deficit to differentiate wheat genotypes for osmoregulation, growth and yield. Annals of Botany, 62, 193-198.

[28] González, A. (2001) Estudio de caracteres fenológicos, agronómicos, morfológicos y fisiológicos en relación con tolerancia al estrés hídrico en cebada. Ph.D. Thesis, Universidad Complutense, Madrid.

[29] Zadoks, J.C., Chang, T.T. and Kozank, C.F. (1974) A decimal code for the growth stages of cereals. Weed Research, 14, 415-421. doi:10.1111/j.1365-3180.1974.tb01084.x

[30] Morgan, J.M., 1983, Osmoregulation as a selection criterion for drought tolerance in wheat. Australian Journal of Agricultural Research, 34, 607-614. doi:10.1071/AR9830607

[31] Dhanda, S.S., Sethi, G.S. and Behl, R.K.(2004) Indices of drought tolerance in wheat genotypes at early stages of plant growth. Journal of Agronomy \& Crop Science, 190, 6-12.

[32] Yagmur, M. and Kaydan, D. (2008) Early seedling growth and relative water content of triticale varieties under osmotic stress of water and $\mathrm{NaCl}$. Research Journal of Agriculture and Biological Sciences, 4, 767-772.

[33] Sánchez, F.J., de Andrés, E.F., Tenorio, J.L. and Ayerbe, L. (2004) Growth of epicotyls, turgor maintenance and osmotic adjustment in pea plants (Pisum sativum L.) subjected to water deficit. Field Crops Research, 86, 81-90. doi:10.1016/S0378-4290(03)00121-7

[34] Turner, N.C. and Jones, M.M. (1980) Turgor maintenance by osmotic adjustment: A review and evaluation. In: Turner, N.C. and Kramer, P.J., Eds., Adaptation of plants to water and high temperature stress, John Wiley \& Sons, Hoboken, 87-104.

[35] Kusaka, M., Garcia Lalusin, A. and Fujimura, T. (2005) The maintenance of growth and turgor in pearl millet (Pennisetum glaucum L.) cultivars with different root structures and osmo-regulation under drought stress. Plant Science, 168, 1-14. doi:10.1016/j.plantsci.2004.06.021

[36] Guóth, A., Benyó, D., Csiszár, J., Gallé, A., Horváth, F., Cseuz, L., Erdei, L. and Tari, I. (2010) Relationship between osmotic stress-induced abscisic acid accumulation, biomass production and plant growth in drought-tolerant and sensitive wheat cultivars. Acta Physiologiae Plantarum, 32, 719-727. doi:10.1007/s11738-009-0453-6

[37] Chimenti, C.A. and Hall, A.J. (1993) Genetic variation and changes with ontogeny of osmotic adjustment in sunflower (Helianthus annuus L.). Euphytica, 71, 201-210. doi:10.1007/BF00040409 